Artvin Çoruh Üniversitesi

Orman Fakültesi Dergisi

ISSN:2146-1880, e-ISSN: 2146-698X

Yıl: 2020, Cilt: 21, Sayı:2, Sayfa:135-142

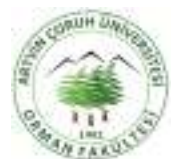

ofd.artvin.edu.t
Artvin Coruh University

Journal of Forestry Faculty

ISSN:2146-1880, e-ISSN: 2146-698X

Year: 2020 Vol: 21, Issue: 2, Pages: 135-142

(c) (1)

\title{
Çay budama atık biyokütlesinin linyit kömür ile karıştırılarak beraber yanma potansiyelinin araştırılması
}

\author{
Investigation of combustion potential of tea pruning waste biomass mixed with lignite coal
}

\section{Halbay TURUMTAY}

Enerji Sistemleri Mühendisliği Bölümü, Karadeniz Teknik Üniversitesi, Trabzon/TURKEY

\section{Eser Bilgisi / Article Info}

Araştırma makalesi / Research article

DOI: 10.17474/artvinofd.655079

Sorumlu yazar / Corresponding author

Halbay TURUMTAY

e-mail: hturumtay@gmail.com

Geliş tarihi / Received

04.12.2019

Düzeltme tarihi / Received in revised form

03.03.2020

Kabul / Accepted

13.03.2020

Elektronik erişim / Online available

02.05.2020

Anahtar kelimeler:

Çay Budama Atığı

Linyit Kömür

Isıl Değer

Kül içeriği

\section{Keywords:}

Tea Pruning Waste Biomass

Lignite Coal

Thermal Value

Ash Content

\begin{abstract}
Özet
Hayat standartlarının artmasına paralel olarak artan enerji gereksinimi enerjide dışa bağımlı olan ülkeler için önemli bir sorundur. Artan enerji talebini karşılarken çevreye verilecek olan zararın en aza indirgenmesi öncelikli hedefler arasında yer almaktadır. Kömür ile ile çalışan termik santrallerden elde edilen enerji ülkemizin enerji ihtiyacının \%32'sini karşılamaktadır. Kullanılan kömürün büyük bir kısmı ithal kömür ve taşkömürüdür. Ülkemizde son yıllarda yapılan çalışmalar sonucunda linyit kömür rezervimiz 16 milyar tonun üzerine çıkmıştır. Fakat bu linyit kömür çoğunlukla düşük kalorili olup, yüksek oranda kükürt, nem ve kül içeriklidir. Bu tür ısıl değeri düşük çevresel etkisi fazla olan kömür kaynaklarının verimli bir şekilde kullanımı için ileri teknolojilerin geliştirilmesi ulusal ve uluslararası düzeyde bir gerekliliktir. Diğer yandan, ülkemizin sahip olduğu biyokütle enerjisi potansiyeli verimli bir şekilde değerlendirilememektedir. Doğu Karadeniz bölgesinin önemli tarımsal atığı olan çay budama atıkları linyit kömür ile belirli oranlarda harmanlanarak karışımın ısıl değeri, kül içeriği, kükürt ve uçucu madde içeriği tespit edilmiştir. Çay budama atı̆̆ının ısıl değeri linyit kömüründen yaklaşık olarak \%30 az olmasına rağmen, linyit kömür ile \%50 oranında harmanlandığında kül içeriği \%12'lerden \%6'lara, kükürt içeriği ise $\% 1.15^{\prime}$ lerden $\% 0.69$ 'lara düşmüştür. Atık olarak kullanılan ve ekonomiye kazandırılmayan bu tarımsal atıkların, linyit kömürü ile uygun karışım değerleri ile homojen şekilde harmanlandığında enerji potansiyellerinin yüksek olduğu ve çevreci bir yakıt olduğu belirlenmiştir.
\end{abstract}

\begin{abstract}
The growing energy requirement in parallel with the increase in living standards is a major problem for countries which are dependent on foreign sources for energy. Reducing the damage effect to the environment while meeting increasing energy demand is among the priority targets. The energy obtained from coal-fired thermal power plants accounts for $32 \%$ of our country's energy needs. Most of the used coal are imported coal and hard coal in our country. The lignite reserves that have been known in recent years by exploration studies have exceeded 16 billion tons in our country. However, these lignite's are generally low calorie, high sulfur, moisture and ash content. The development of unique designs and / or technologies for the effective evaluation of such coal at national and international level are needed. On the other hand, there is an important biomass potential in our country; this potential is still not being assessed effectively and efficiently. Tea pruning wastes, which are important agricultural wastes of the Eastern Black Sea region, were blended with lignite coal at certain ratios and the content of the mixture was determined for colorimetric value, ash content, sulfur content and volatile matter content. Although the tea pruning waste thermal value was approximately $30 \%$ lower than the lignite, $50 \%$ blended biomass with lignite coal, ash content decreased from $12 \%$ to $6 \%$ and sulfur content decreased from $1.15 \%$ to $0.69 \%$. It was determined that these agricultural wastes, which were used as waste and not used in industry, have a high energy potential and an environmentally friendly fuel when they are homogeneously blended with lignite coal.
\end{abstract}

\section{GiRiş}

Gelişen yaşam standartları ve buna bağıı olarak artan enerji talebi son yıllarda ülkelerin birinci gündemi olmaktadır. Artan bu yüksek enerji talebini hem sınırlı hem de çevre üzerine olumsuz etkileri olan fosil enerji kaynaklarına alternatif kaynak arayışları son yıllarda büyük bir ivme kazanmıştır (Shafiee ve Topal 2009).
Özellikle ülkemiz gibi enerji talebini karşılamada dışa bağlı olan ülkelerde enerji ithalatına ödenen büyük miktarda paranın aşağı çekilmesi yerel kaynakların değerlendirilmesiyle mümkün olabilecektir. Ülkemiz bulunduğu coğrafik konumu sebebiyle linyit, taş kömürü, ham petrol, doğalgaz gibi fosil kaynak rezervleri, 
uranyum ve toryum gibi nükleer yakıt rezervleri ve hidrolik enerji, güneş enerjisi, jeotermal enerji, biyokütle enerjisi, dalga enerjisi ve rüzgâr enerjisi gibi yenilenebilir enerji kaynaklarına sahiptir (Demirbaş 2001, Apergis ve Payne 2010, Öztürk ve Acaravci 2010). Fosil yakıtlar bakımından linyit kömür hariç zengin rezervlere sahip olmayan Türkiye'de, 2008 yılından bu tarafa birincil enerji tüketiminde en büyük pay doğal gaz tarafından tedarik edilen kaynaklara aittir. Yerli üretimi oldukça düşük seviyelerde olan ve büyük oranda ithal edilen doğal gaz kaynağına aşırı bağımlı olunması, ülkemizi önemli bir arz güvenliği riski ile karşı karşıya bırakmaktadır. Ülkemizde, oldukça sınırlı doğal gaz ve petrol rezervlerine karşın, 560 milyon tonu görünür olmak üzere yaklaşık 1.3 milyar ton taşkömürü ve 16 milyar ton linyit rezervi bulunmaktadır (Demirbaş 2002, Koç ve Şenel 2013). Linyit rezervleri bir noktada toplanmış olmayıp ülke geneline yayılmıştır. Neredeyse bütün coğrafi bölgelerde linyit kömür rezervlerine rastlanılmaktadır. Bu rezervler dünya kömür rezervinin yaklaşık \%2'sini oluşturmaktadır. Dünya linyit üretiminin ise yaklaşık olarak \%8'i Türkiye'de yapılmaktadır. Ülkemizde çıkartılan linyit kömürünü ise genellikle termik santrallerde yakarak elektrik üretiminde kullanılmaktayız. Fakat linyit kömürünün ısıl veriminin düşük oluşu ve yüksek kül ve kükürt içeriği sebebiyle yakıldığında çevreye olumsuz etkileri vardır (Kök 2005, Kastanaki ve Vamvuka 2006, Güler 2011). Bu çerçevede, linyit potansiyelinin değerlendirilmesi için uygun ve temiz teknolojilerin geliştirilmesi, ülkemizin öncelikli enerji politikaları arasında yer almaktadır (Tamzok 2011).

Yerli yenilenebilir enerji kaynaklarımız içinde biyokütle giderek arttırılabilecek potansiyeli ile öne çıkmaktadır. Enerji üretimi amacıyla kullanılan biyolojik kaynakların en önemlileri odun (enerji ormanları, ağaç artıkları), yağıı tohum bitkileri (ayçiçek, kolza, soya, aspir, pamuk, v.b), karbo-hidrat bitkileri (patates, buğday, mısır, pancar, şekerkamışı, v.b), elyaf bitkileri (keten, kenaf, kenevir, sorgum, vb.), bitkisel atıklar (dal, sap, saman, kök, kabuk v.b), hayvansal atıklar ile şehirsel ve endüstriyel atıklardır
(Saraçoğlu 2007, Bilgen ve ark. 2008, Demirbaş ve ark. 2009). Bir tarım ülkesi olan Türkiye'de tarımsal atıklar oldukça fazladır. OECD ülkeleri arasında Türkiye, tarımsal atıklarından hesaplanan toplam enerji potansiyelinde 9.5 milyon ton petrol eşdeğeriyle (MTEP) dördüncü sırada yer almaktadır. Sahip olduğu büyük potansiyeli, farklı sosyal ve ekonomik faydaları nedeniyle biyokütle en önemli yenilenebilir enerji kaynaklarından birisidir (Kaygusuz ve Türker 2002, Balat 2005, Kaygusuz 2010, Toklu 2017). Biyokütle, doğrudan ısınma ve elektrik üretmek amacıyla kullanılabilmekte; katı, sıvı ve gaz yakıta çevrilebilmektedir (Açma 2003, Karayiğit ve Köksoy 1998, Demirbaş 2002).

Türkiye'de çay tarımı, Doğu Karadeniz Bölgesi'nde başta Rize olmak üzere Ordu, Giresun, Trabzon ve Artvin illerinde yapılmaktadır. Türkiye'de çay tarımı, 205 bin üretici tarafından, 759 bin dekar (ruhsatlı) alanda küçük aile işletmeciliği şeklinde yapılmaktadır. Çay Doğu Karadeniz Bölgesi'nde yaşayan halkın en önemli gelir kaynaklarından birisini teşkil etmektedir. Çay üretimi bölge ve Türkiye ekonomisinde son derece önemli bir yer tutmaktadır (Alkan ve ark. 2009). Çay bitkisi doğada gelişmeye bırakıldığında ağaç şekline dönüşür. Böyle bir durum yaprak hasadını güçleştirdiği gibi, sürgün verimini de düşürmektedir. Bu nedenle çay bitkisi, toprağa yakın yükseklikte dallandırarak, düzgün bir toplama seviyesi ve bol sürgün oluşumunu sağlamak amacıyla budamaya tabi tutulur (Kaçar 1992, Torun ve Taluğ 2005).

Üreticilerin her yıl çaylıklarının \%10'nu budaması zorunludur. Şekil 1'de gösterilen resimde de görüleceğ üzere her yıl bahar döneminde çay bahçelerinde budama işlemleri gerçekleştirilmektedir. Bu şekilde açığa çıkan atık biyokütle kullanım alanı olmadığı için genelde sahada yakılmak suretiyle yok edilmektedir. Yıllık yaklaşık olarak 70 bin dekarlık alan budanmakta ve açığa çıkan atık çay çalıları genellikle çaylıklarda yakılmaktadır. Yaklaşık 70 bin dekarlık alandan çıkan bu devasa atık biyokütlenin değerlendirilmesi ve sanayiye kazandırılması önem arz etmektedir. 

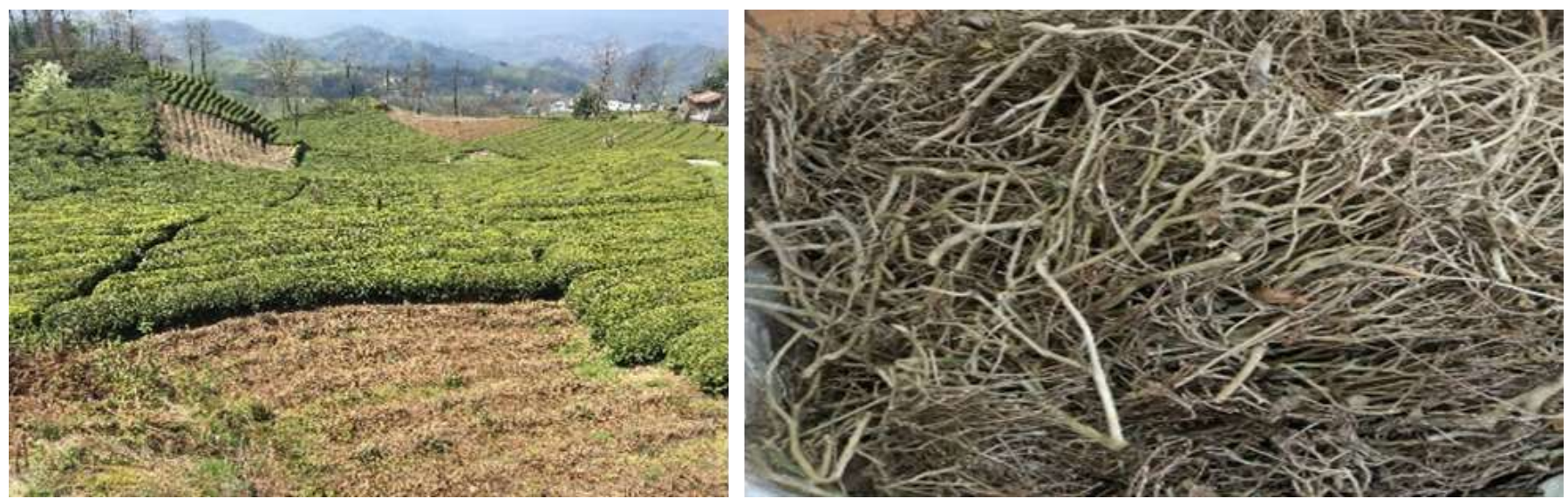

Şekil 1. (A)Rize ilinde budama yapıımış bir çay bahçesinden görüntü (B) Budama sonunda elde edilen atık çay çalısı

Önemli bir fosil yakıt olan kömürün biyokütle ile harmanlanarak yakılması temiz ve ucuz enerji elde edilmesinde alanında umut vermektedir. Kömürün \%20 oranında biyokütle ile beraber yakılması kazan verimliliğini artırmakla kalmayıp yakıt maliyetini, azot oksit $\left(\mathrm{NO}_{\mathrm{x}}\right)$ ve karbondioksit $\left(\mathrm{CO}_{2}\right)$ salınımını azalmaktadır (Demirbaş 2003). Kömür ile \%10-30 arasında pirinç ve bambu karıştırılarak oluşturan karışımlar yanma sonucu açığa çıkan ıSı miktarını düşürmesine rağmen karbon monoksit (CO), karbon dioksit $\left(\mathrm{CO}_{2}\right)$, azot oksit $\left(\mathrm{NO}_{\mathrm{x}}\right)$ ve sülfür dioksit $\left(\mathrm{SO}_{2}\right)$ salınımlarını azaltmıştır (Kwong ve ark. 2007). Linyit ve mısır koçanının \%50, \%50 karıştırılmasıyla gerçekleştirilen beraber yanma (cofiring) testleri sıvı ve gaz üretiminde biyokütle kömür karışımının sinerjik bir etkiye sahip olduğunu göstermiştir (Sonobe ve ark. 2008). Ülkemiz için önemli bir tarımsal atık olan fındık kabuğu ile Elbistan linyit kömüründen oluşturulan karışımda ağırlıkça \%8'e kadar fındık kabuğunun eklenmesi, beklenen teorik yanma ısısından daha yüksek yanmanın gerçekleșmesini sağlamıștır. Bununla birlikte, ağırlıkça \%10 biyokütle ilavesi, yanma etkisi üzerinde azaltıcı bir rol oynamıştır (Haykiri Açma ve Yaman 2008). Bununla birlikte farklı oranlarda inek gübresi ile karıştırılmış kullanılmış çay atıklarının biyogaz üretimine olumlu katkıları tespit edilmiştir (Khayum ve ark. 2018). Manyuchi ver ark. (2018) yapmış olduğu çalışmada ise çay atıklarından elde edilen biyobiriketlerin yaklaşık $5254 \mathrm{kCal} / \mathrm{kg}$ Isıl değere ve \%10'dan daha az bir neme sahip olduğu bulunmuştur.

Geniş linyit rezervlerine ve tarımsal atıklara sahip ülkemizin enerji bağımlılığının azaltılması bakımından önem arz eden kömür ve biyokütle yaygın olarak beraber yakılarak değerlendirilmektedir. $\mathrm{Bu}$ beraber yanmalarında hedef ısıl kayıp olmadan daha az miktarda kükürt ve kül salınımını sağlamaktır. Özellikle son yıllarda, linyit kömürü ile beraber yanabilecek yeni biyokütlelerin arayışı devam etmektedir. Bu araştırma makalesinde Doğu Karadeniz bölgesinin önemli tarımsal atığı olan çay budama atıklarının farklı oranlarda linyit kömür ile karıştırılarak beraber yanma potansiyeli ilk defa araştırımıştır.

\section{MATERYAL VE YÖNTEM}

Yapılan çalışmalar kapsamında, çay bitkisinin budama atıkları Rize'de yerel bir çay bahçesinde sağlanmıştır.

Kullanılan linyit kömürü ise Türkiye Kömür İşletmeleri Kurumu Genel Müdürlüğü tarafından tedarik edilen Soma Kısrakdere yıkanmış linyit kömürüdür.

\section{Çay Budama Atık Biyokütlesinin Hazırlanması}

Çay tarımının yoğun olarak yapıldığı illerin başında gelen Rize'den yerel bir çay üreticisinden çay budama atığı olan biyokütle temin edilmiştir. Şekil 1B' de görüldüğü üzere çay biyokütlesinde farklı kalınlıklarda dal örnekleri bulunmaktadır.

Rize ilinden sağlanan çay budama atıkları parçacık boyutu $4 \mathrm{~mm}$ olacak şekilde öğütülmüştür. Öğütülme işleminin ardından analiz için, daha önceden belirlenmiş numune oranlarda olmak koşuluyla biyokütle kömür karışımları homojen bir şekilde karıştırılmıştır. Ortam koşullarından ve özellikle nemden korumak için muhafaza edilmiştir. 


\section{Biyokütle Kömür Karışımlarının Hazırlanması}

Çay atık biyokütle linyit kömür karışımlarının beraber yanma özelliklerini incelemek için biyokütle numuneleri, Soma linyit kömür ile karıştırılmıştır. Çay atık biyokütle miktarları Şekil 2'de görüleceği üzere $\% 100$, \%80, \%50 ve \%20 olacak şekilde linyit kömürü ile karıştırılarak hazırlanmıştır.

\section{Biyokütle Kömür Karışımının Yanma Davranışının Incelenmesi}

Kömür-biyokütle karışımları, kömür numunelerine ağırlıkça $\% 20, \% 50, \% 80$ ve $\% 100$ oranlarında biyokütle numuneleri ilave edilerek hazırlanmıştır. Kömür ve biyokütle numunelerinin yakıt özelliklerini belirlemek amacıyla ısıl değer ölçümleri D 5865 ISO 1928, uçucu madde D 3175, kül D 3174 ve kükürt analizleri D 4239 ASTM standartlarına uygun olarak yapılmıştır.
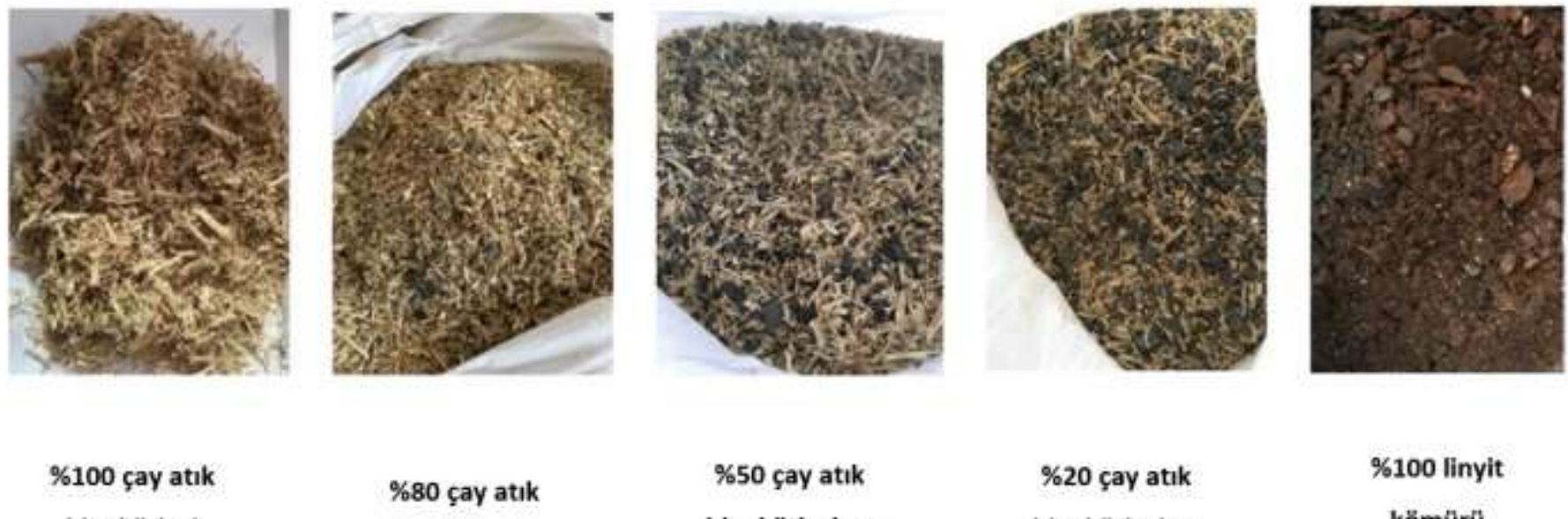

biyokütlesi

$$
\begin{gathered}
\% 80 \text { çay atık } \\
\text { biyokütlesi ve } \\
\% 20 \text { linyit kömürü }
\end{gathered}
$$

\%50 çay atık

biyokütlesi ve

$\% 50$ linyit kömürü
$\% 20$ çay atık

biyokütlesi ve

\%80 linyit kömürủ

Şekil 2. Farklı oranlarda kömür ile karıştırılmış biyokütle karışım numuneleri

\section{BULGULAR VE TARTIŞMA}

\section{Çay Budama Atık Biyokütle - Linyit Kömür Karışımlarının Isıl (kalorifik) Değerleri}

Çay atık biyokütlesi ile linyit kömürün farklı oranlarda karıştııılması ile elde edilen karışımların alt ve üst ısıl değerleri tayin edilmiştir. Çizelge 1 'de verilen değerlere bakıldığında çay atık biyokütlesinin yaklaşık 4000 $\mathrm{kCal} / \mathrm{kg}^{\prime} \mid \mathrm{lk}$ ısıl değere sahip olduğu tespit edilmiştir. Bu değer piyasada işlem gören çoğu linyit kömürüne yakın bir değerdir. Çay atık biyokütlesinin, linyit kömürü ile karıştırılan numunelerinin linyit oranı arttıkça $ı s ı \mid$ değerlerinin arttığı belirlenmiştir. Çizelge 1.'de görüldügü gibi biyokütle kömür karışımlarının uygun oranlama sağlanarak ısıl değerinde ciddi bir düşüş olmadan yakıt olarak kullanılma potansiyeli olduğu ortaya çıkmaktadır. Demirbaş (2003) yılında yapmış olduğu akademik çalışmada mısır koçanının, ayçiçek sapının, badem kabuğunun, pamuk sapının, yer fıstığı kabuğunun, arpa samanının, pirinç samanının, tütün tozunun ve pirinç kabuğu birçok tarımsal atığın ısıl değerini $1030 \mathrm{kCal} / \mathrm{kg}-2240 \mathrm{kCal} / \mathrm{kg}$ arasında olduğunu bildirmiştir. Doğu Karadeniz bölgesinin ekonomik olarak önemli ürünlerinden biri olan fındıktan elde edilen bir tarımsal atık olan fındık zurufunun biriketlenmesiyle elde edilen ortalama alt Isıl değeri $4232 \mathrm{cal} / \mathrm{g}$ olarak tespit edilmiştir (Demirel ve Gürdil 2018). Zengin ve ark. (2020) yapmıs olduğu çalışmada ise kavak odun atıklarından elde edilen peletlerin ısıl değeri $4515 \mathrm{cal} / \mathrm{g}$ olarak ölçülmüştür. Peletleme ve biriketleme tarımsal atıkların ısıl değerini artırmasına rağmen ekonomik açıdan biyokütle maliyetini artıran bir süreçtir. Bizim yapmış olduğumuz çalışmada ise herhangi bir işleme tabi 
tutulmadan kullanılan çay budama atıkları 4000 $\mathrm{kCal} / \mathrm{kg}^{\prime}$ Ilk bir ısıl değer ortaya çıkarmıştır. Ülkemiz için önemli bir tarımsal atık olan fındık kabuğunun ısıl değeri ise $4358 \mathrm{kCal} / \mathrm{kg}^{\prime}$ dır (Haykiri Açma ve Yaman, 2008). Bizim elde ettiğimiz $4000 \mathrm{kCal} / \mathrm{kg}^{\prime}$ lık ısıl değer fındık kabuğuna oldukça yakın değerdir. Bu çalışma sonucunda tespit edilen ısıl değerler literatürdeki bilgilerle uyuşmaktadır. İyi bir yakıtın en önemli özelliklerinden birisi ısıl değerin yüksek olmasıdır. Buna göre çay budama atığının ısıl değer bakımından oldukça iyi bir yakıt olduğu söylenebilir.

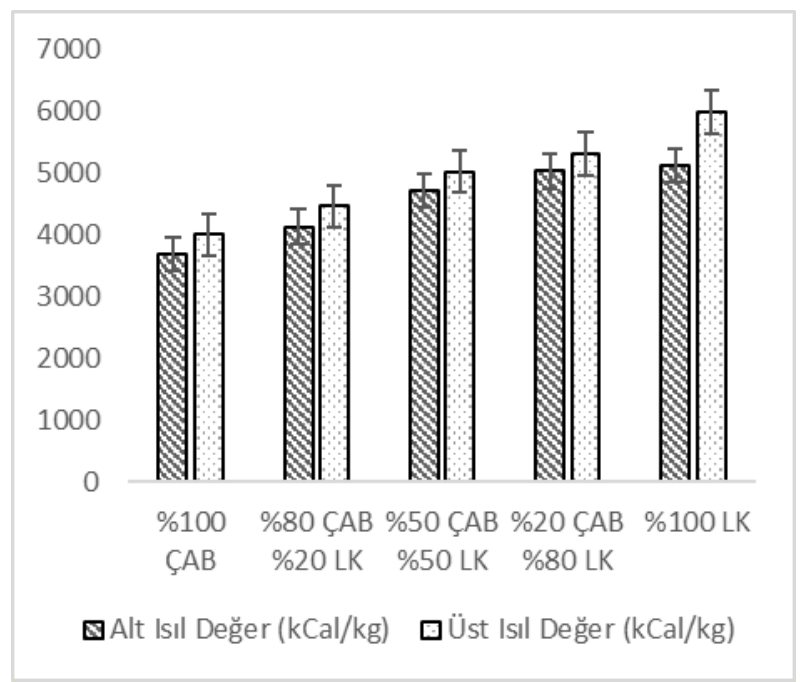

Çizelge 1. Çay atık biyokütle ile linyit kömür karışımlarının alt ve üst Isıl değerlerinin $\mathrm{kCal} / \mathrm{kg}$ cinsinden değerleri (ÇAB: Çay Atık Biyokütle, LK: Linyit Kömür)

\section{Çay Budama Atık Biyokütle - Linyit Kömür Karışımlarının Uçucu Madde Oranları}

Kömürlerdeki uçucu madde oranının düşük olması kömürün verimli bir şekilde yanmasını engellerken, bu oranın yüksek olması ise havanın aşırı kirlenmesine sebep olur. Genç linyitlerde uçucu madde oranı yaklaşık olarak \%50 çıktığı hâlde antrasit gibi yaşlı kömürlerde bu oran \%10'dan azdır. Taş kömürlerinde ise uçucu madde oranı yaklaşık olarak \%10-45 arasında değişmektedir. Ortalama olarak bu değer \%30 olarak kabul edilebilir. Uçucu madde miktarı fazla olan linyit tipi kömürlerin yanmasında hava karışımı iyi ayarlanmadığı durumlarda ocaklarda ve borularda is oluşumu sıklıkla görülür. Uçucu madde miktarı \%10'un altında olan kömürlerin tutuşturabilmesi güçleşir (Böke ve ark. 2010). Literatürdeki çalışmalarda tarımsal atık olan fındık kabuğunun, mısır koçanının, pirinç kabuğunun ve buğday sapının uçucu madde miktarı sırasıyla \%87.3, \%82.2, \%64.4, \%66.8 olarak tespit edilmiştir (Haykiri Açma 2008, Demirel ve Gürdil 2018, Sonobe ve ark. 2008, Kwong ve ark. 2007, Wang ve ark. 2009). Gerçekleştirilen analizlerde Çizelge 2.'de görüleceği üzere saf çay atık biyokütlenin uçucu madde oranı literatür ile uyumlu olarak \%70.59 ölçülmüştür. Uçucu madde oranının yüksek olması çay atık biyokütlesinin tek başına yanmasına engel oluşturur ve yanma sonu emisyonları olarak çevre açısından tehdit oluşturabilmektedir. Fakat çay atık biyokütlesinin linyit kömürü ile karıştırılan karışımlarının uçucu madde oranları linyit kömürü miktarının artması ile doğru orantılı olarak azalma eğilimi göstermiştir.

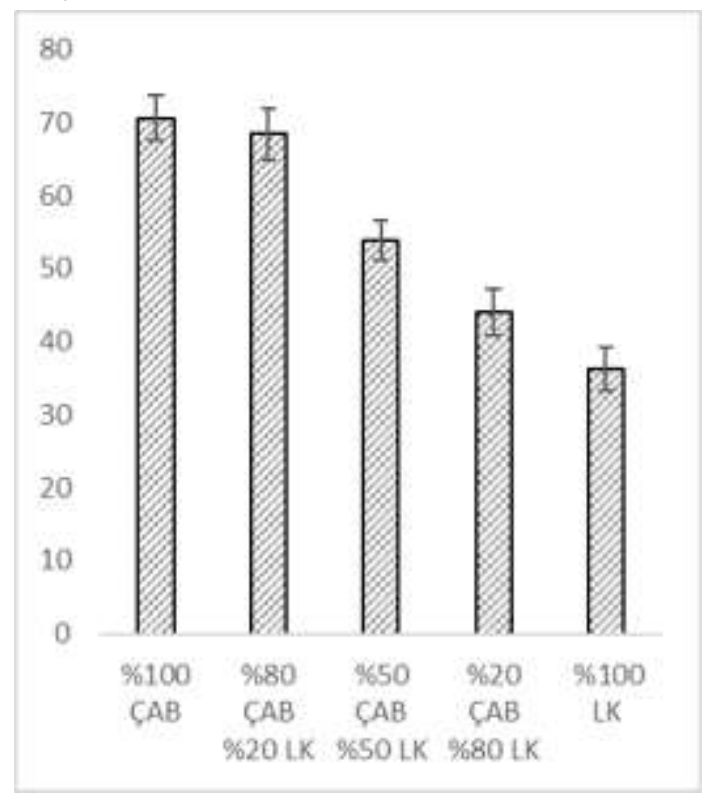

Çizelge 2. Çay budama atık biyokütlesi ile linyit kömür karışımlarının içerdiği uçucu madde oranının yüzdece ifade edilmesi (ÇAB: Çay Atık Biyokütle, LK: Linyit Kömür).

\section{Çay Budama Atık Biyokütle - Linyit Kömür Karışımlarının Kül Oranı}

Çay budama atığının saf halinin kül oranı yaklaşık olarak \%1.19'dur. Yapılan analizler sonucunda biyokütle ilave edilmesi ile oluşturulan karışımların kül oranları, tek başına kömür numunelerinin kül oranlarından düşüktür. Kömürde kül oranı düştükçe kalori oranı artar. Kaliteli yerli kömürlerde de kül oranının yaklaşık olarak \%20'i geçmemesi beklenilir (Bayat 1998, Ilic ve ark. 2003). Geçmiş yıllarda yapılan çalışmalarda tarımsal atık olan fındık kabuğunun, fındık zurufu, mısır koçanının, pirinç 
kabuğunun ve buğday sapının kül oranın sırasıyla \%4.3, \%10.65, \%0.9, \%8.93, \%9.28 olarak analiz edilmiştir (Haykiri Açma 2008, Demirel ve Gürdil 2018, Sonobe ve ark. 2008, Kwong ve ark. 2007, Wang ve ark. 2009). Çizelge 3.' de görüldüğü gibi, yapılan analizler sonucunda linyit kömürünün kül oranı $\% 11.66$ olarak tespit edilmiştir. Linyit kömürüne sırasıyla \%20 çay budama atığı eklenmesi ile oluşan karışımın kükürt değeri; $\% 10.19$ 'a, $\% 50$ oranında çay budama atığı eklendiğinde ise \%6.67'e düşmüştür. Yapılan analizler sonucunda saf linyit kömürüne çay budama atığı eklenmesi ile oluşturulan biyokütle-kömür karışımının kül oranı, saf linyit kömürünün kül değerine göre daha düşük elde edilmiştir. Çay budama atıkları ise \%1.19 değerle mısır koçanı gibi oldukça düşük kül içeriğine sahiptir.

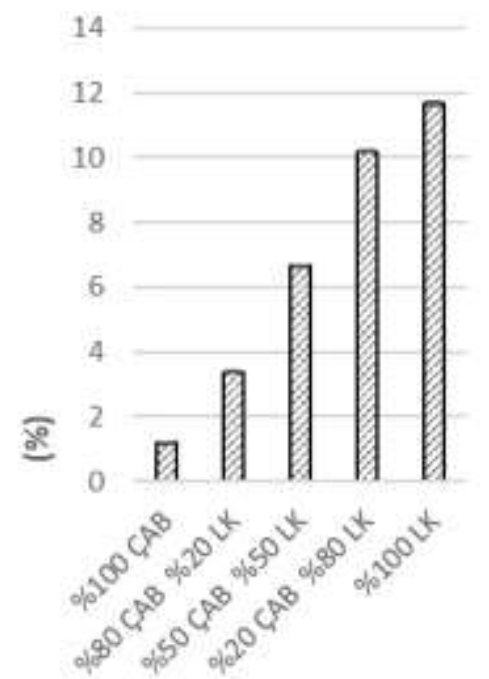

Çizelge 3. Çay atık biyokütlesi ile linyit kömür karışımlarının kül oranının yüzdece ifade edilmesi (ÇAB: Çay Atık Biyokütle, LK: Linyit Kömür).

\section{Çay Budama Atık Biyokütle - Linyit Kömür Karışımlarının Kükürt Oranı}

Kükürt kimyasal olarak yanabilen bir madde olduğundan kömürün ısıl değerini azaltıcı bir etki yapmaz. Ancak yanan kükürt çevre açısından en büyük kirleticilerden biridir. Bununla birlikte kükürt yanma odası, kazan ve borularda korozif bir etkiye sahiptir. Kömürlerin gerek termik santrallerde gerekse endüstri ve ısınmada enerji kaynağı olarak kullanılmaları sırasında çevreyi mümkün olan en düşük düzeyde kirletmelerini sağlamak amacıyla, kül ve piritik kükürdünün uzaklaştırılarak kalitelerinin iyileştirilmesi zorunludur (Lin Chou 2012). Çizelge 4.' de görüldüğü gibi, yapılan analizlerde linyit kömürünün kükürt değeri $\% 1.15$ dir. Linyit kömürüne $\% 50$ çay budama atığı eklenmesi ile oluşan karışımın kükürt değeri \%0.69 olarak tespit edilmiştir. Saf linyit kömürüne çay budama atığı eklenmesi ile oluşturulan biyokütle karışımının kükürt değeri, saf linyit kömürünün kükürt değerine göre daha düşüktür. Fındık kabuğunun, mısır koçanının, pirinç kabuğunun ve buğday sapının kükürt oranı sırasıyla $\% 0.05, \% 0.01, \% 0.12, \% 0.4$ olarak literatüre geçmiştir (Haykiri Açma 2008, Sonobe ve ark. 2008, Kwong ve ark. 2007, Wang ve ark. 2009). Çay budama atığının saf halinin kükürt değeri ise \%0.05 olarak ölçülerek literatürde verilen diğer tarımsal atıklarla uyumlu olduğu gözlemlenmiştir. Sonuç olarak, biyokütle ilave edilmesi ile oluşturulan kömür karışımların kükürt değerleri, tek başına kömür numunelerinin kükürt değerlerinden düşük olmaktadır ki buda kömürün yanmasının çevreye vermiş olduğu olumsuz etkileri azaltabilecektir.

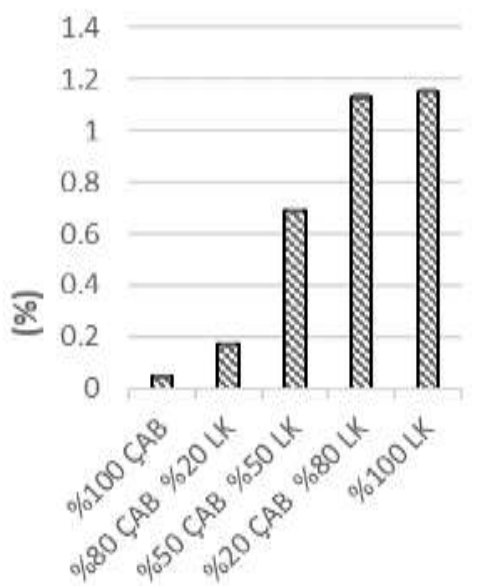

Çizelge 4. Çay atık biyokütlesi ile linyit kömür karışımlarının kükürt oranının yüzdece ifade edilmesi(ÇAB: Çay Atık Biyokütle, LK: Linyit Kömür).

\section{SONUÇ}

Ülkemizdeki ulusal kaynaklarımızı enerji üretiminde daha fazla kullanabilmek amacı ile düşük ısıl değerli Türk linyitleri ile çay budama atıklarından elde edilen biyokütlenin, belirli oranlardaki karışımlarının yakıt potansiyellerini bu çalışmada belirlenmiştir. Yapılan çalışmada çay budama atık biyokütlesinin ısıl değeri ve kül miktarı sırasıyla $4000 \mathrm{kCal} / \mathrm{kg}$ ve $\% 1.19$ dur. Çay budama atık biyokütlesinin uçucu madde oranı ve kükürt oranı ise sırasıyla \%35 ve \%0.05 olarak tespit edilmiştir. 
Peletleme ve biriketleme tarımsal atıkların ısıl değerini artırmasına rağmen ekonomik açıdan biyokütle maliyetini artıran bir süreçtir. Bizim yapmış olduğumuz çalışmada ise herhangi bir işleme tabi tutulmadan kullanılan çay budama atıkları $4000 \mathrm{kCal} / \mathrm{kg}^{\prime} \mid \mathrm{kk}$ bir ısı değer ortaya çıkarmıştır. Bu değer ülkemizde kullanılan birçok linyit kömürden daha yüksek bir değerdir. Bu anlamda çay budama atıklarının tek başına bile katı yakıtla çalışan yakma sistemlerinde alternatif enerji kaynağı olarak kullanılmasının uygun olacağı düşünülmektedir.

Saf linyit kömürüne belirlenen oranlarda çay bitkisi budama atıkları eklenmesiyle oluşturulan karışımların yanma sonu emisyon değerlerinde ciddi düşüşler gerçekleşmiştir. Saf linyit kömürüne göre, hazırlanan biyokütle karışımlarının kükürt ve kül oranlarında yüksek düşüş gerçekleşmiştir. Çay bitkisi budama atıklarının ısıl değeri belirlenmiştir. Çay budama atığının ısıl değeri linyit kömüründen yaklaşık olarak \%30 az olmasına karşın düşük kül ve kükürt içeriği sebebiyle oldukça çevrecidir. Çay budama atığının linyit kömür ile \%50 oranında harmanlandığında kül içeriği \%12'lerden \%6'lara, kükürt içeriği ise $\% 1.15^{\prime}$ lerden $\% 0.69$ 'lara düşmüştür. Atık olarak kullanılan ve ekonomiye kazandırılmayan bu atıkların, linyit kömürü ile uygun karışım değerleri ile homojen şekilde harmanlandığında enerji potansiyellerinin yüksek olduğu ve çevreci bir yakıt olduğu belirlenmiştir.

Fosil yakıt kaynaklarına göre daha ucuz bir enerji kaynağı olan ve ülkemizde önemli bir potansiyele sahip olan çay budama atık biyokütlesinin, linyit kömür ile \%50 oranında karıştırılarak katı yakıt olarak, ya da harmanlanarak ortak yakma işlemi ile termik santral vb. işlemlerde kullanılması, ülkemizin enerji ihtiyacının karşılanması için önemli bir alternatif yakıt olacaktır. Bu şekilde hem maliyet indirimi, hem de çevresel kirliliğin azaltılması sağlanacaktır. Bu çalışma ile özellikle doğu Karadeniz bölgesinde atık biyokütlenin düşük kalorili linyit kömürü harmanlanmasıyla beraber yanma potansiyellerinin daha yüksek, daha çevreci alternatif bir katı yakıt haline dönüştürülebileceği ilk defa ortaya konmuştur.

\section{TEŞEKKÜR}

Bu çalışmada yardımlarını esirgemeyen Uğur Eylem KARAKAŞ'a teşekkürleri sunuyorum. Bu çalışma, TÜBITAK "2209-B Sanayiye Yönelik Lisans Bitirme Tezi Destekleme Programı” tarafından desteklenmiştir

\section{KAYNAKÇA}

Açma HHH (2003) Combustion characteristics of different biomass materials. Energy Conversion Management 44: 155-162

Apergis N, Payne JE (2010) Renewable energy consumption and economic growth: evidence from a panel of OECD countries, Energy policy, 38:656-660

ASTM D3177-02 (2007) Standard Test Methods for Total Sulfur in the Analysis Sample of Coal and Coke (Withdrawn 2012) ASTM International, West Conshohocken, PA

ASTM-E 1755 (1995) Ash in Biomass, Annual Book of ASTM Standards.

ASTM-E 711 (1987) Gross Calorific Value of Refuse-Derived Fuel by the Bomb Calorimeter, Annual Book of ASTM Standards.

ASTM-E 872 (1982) Volatile Matter in the Analysis of Particulate Wood Fuels, Annual Book of ASTM Standards

Bayat O (1998) Characterization of Turkish fly ash. Fuel 77: 1059-1066

Bilgen S, Keles S, Kaygusuz A, Sarı A, Kaygusuz K (2008) Global warming and renewable energy sources for sustainable development: a case study in Turkey. Renewable and Sustainable Energy 12 : 372-396

Böke E, Okutan H, Erdöl Aydın N (2010) Effect of Coal Volatile Matter on Emissions of Boiler Combustion. Twenty - Seventh Annual International Pittsburgh Coal Conference, Istanbul, Turkey, pp 1313

Lin Chou C (2012) Sulfur in coals: A review of geochemistry and origins. International Journal of Coal Geology 100: 1-13

CLSI (Clinical and Laboratory Standards) (2007) Performance standards for antimicrobial susceptibility testing. 17th Informational Supplement 27:1-1

Demirbaş A (2001) Energy balance, energy sources, energy policy, future developments and energy investments in Turkey. Energy conversion and Management 42:1239-1258

Demirbaş A (2002) Electricity from biomass and hydroelectric development projects in Turkey. Energy Exploration and Exploitation 20: 325-335

Demirbaş A (2003) Sustainable cofiring of biomass with coal, Energy Conversion and Management 44:1465-1479

Demirbaş L (2002) Türkiye'de enerji sektörü, sektörün problemleri, Avrupa birliği ve Türkiye'de enerji politikaları. Süleyman Demire Üniversitesi, Sosyal Bilimler Enstitüsü Yüksek Lisans Tezi, Isparta

Demirbaş MF, Balat M, Balat (2009) Potential contribution of biomass to the sustainable energy development, Energy Conversion and Management 50: 1746-1760

Güler M (2011) Dünyada ve Türkiye'de Kömür. TMMOB 8. Enerji Sempozyumu, İstanbul, pp 211-245.

Demirel B, Gürdil GAK (2018) Fındık zurufu atığından yakıt briketi elde edilmesi ve brikete ait bazı özelliklerin belirlenmesi. Anadolu Journal of Agricultural Science 33:24-29

Haykiri Açma H, Yaman S (2009) Effect of co-combustion on the burnout of lignite/biomass blends: A Turkish case study. Waste Management 28: 2077-2084

Ilic M, Cheeseman C, Sollars C, Knight J (2003) Mineralogy and microstructure of sintered lignite coal fly ash. Fuel 82:3:331-336 
Karayiğit AĠ, Köksoy M (1998) Kömür Özellikleri Teknolojisi ve Çevre ilişkileri, Ed. Özgün O, Kömür Ofset Matbaacılık, İstanbul, 59-81

Kastanaki E, Vamvuka D (2006) A comparative reactivity and kinetic study on the combustion of coal-biomass char blends. Fuel 85:1186-1193

Kaygusuz K, Turker MF (2002) Biomass energy potential in Turkey. Renewable Energy 26: 661-678

Kaygusuz K (2010) Sustainable energy, environmental and agricultural policies in Turkey, Energy Conversion Management. 51:10751084

Khayum N, Anbarasu S, Muruga S (2018) Biogas potential from spent tea waste: A laboratory scale investigation of co-digestion with cow manure. Energy 165:15:760-768

Koç E, Şenel MC (2013) Dünyada ve Türkiye'de Enerji Durumu-Genel Değerlendirme, Mühendis ve Makina 54:32-44

Kök MV (2005) Temperature-controlled combustion and kinetics of different rank coal samples. Journal of Thermal Analysis and Calorimetry volume 79:75-180

Kwonga C, Chaoa C, Wanga J, Cheung C, Kendall G (2007) Cocombustion performance of coal with rice husks and bamboo. Atmospheric Environment 41: 7462-7472
Manyuchi MM, Mbohwa C, Muzenda E (2018) Biogas and Bio solids Production from Tea Waste through Anaerobic Digestion. Proceedings of the International Conference on Industrial Engineering and Operations Management Paris, France, pp 25192522

Özturk I, Acaravcı A (2010) CO2 emissions, energy consumption and economic growth in Turkey. Renewable and Sustainable Energy Reviews 14: 9: 3220-3225

Saracoglu N (2007) Environmentally Friendly Renewable Energy Source: Energy Forestry, Emoenerji. Social News and Research Journal 2:22-35

Shafiee S, Topal E (2009) When will fossil fuel reserves be diminished? Energy Policy 37:1:181-189

Taro Sonobe T, Worasuwannarak N, Pipatmanomai S (2008) Synergies in co-pyrolysis of Thai lignite and corncob. Fuel Processing Technology 89: 1371-1378

Tamzok N (2011) Jeopolitik ve Teknolojik Gelişmeler Perspektifinden Kömürün Geleceği. TMMOB 8. Enerji Sempozyumu, İstanbul, pp 247-291.

Zengin Y, Çelik AE, Dok M, Çolak S (2020) Kavak odun atıklarından elde edilen peletlerin bazı yakıt özelliklerinin belirlenmesi. Artvin Çoruh Üniversitesi Orman Fakültesi Dergisi21:1: 36-2 